Apresentação | Introduction

\title{
O xamanismo e suas múltiplas manifestações e abordagens
}

\section{Shamanism and its multiple expressions and perspectives}

Sergio Baptista da Silva*

* Universidade Federal do Rio Grande do Sul - Porto Alegre, RS, Brasil sergiobaptistadasilva@gmail.com

Emerson Giumbelli ${ }^{* *}$

** Universidade Federal do Rio Grande do Sul - Porto Alegre, RS, Brasil emerson.giumbelliyahoo.com.br

Pablo Quintero***

*** Universidade Federal do Rio Grande do Sul - Porto Alegre, RS, Brasil pquinterom@gmail.com 
Este número de Horizontes Antropológicos dedicado aos sistemas xamânicos e novos xamanismos apresenta um conjunto diversificado de artigos, que bem expressam o amplo e variado espectro de suas ocorrências e caracterizações, e as múltiplas possibilidades de abordagem que o campo da antropologia vem proporcionando.

Historicamente, a própria constituição desse campo encontrou nos estudos sobre o xamanismo nas chamadas sociedades tradicionais uma atraente, desafiadora e, ao mesmo tempo, difusa referência para reflexões e interrogações (Langdon, 1996). Até há bem poucas décadas considerada como uma instituição arcaica e plena de práticas "mágicas" e "tradicionais", novas abordagens têm evidenciado sua força e presença em contextos atuais.

Essas características encontram uma ótima ilustração na história dos termos que cercam nosso tema. "Xamã" é uma palavra originária de línguas do leste da Sibéria, onde viviam povos que desde o século XVII foram objetos de relatos. Mas é só no século XX que se forja a categoria "xamanismo" para dar uma expressão translocal a certas técnicas que conjugam elementos materiais e espirituais. As últimas décadas do século XX assistem a uma generalização de outra ordem, que projeta o termo para além da antropologia e dos estudos religiosos. No século XXI, ao mesmo tempo em que parece haver pouco acordo sobre o que seja xamanismo, constatamos a potência da palavra - e suas variantes - para designar e acompanhar realidades muito variadas, compostas de agentes, agências e agenciamentos surpreendentemente heterogêneos.

Essas constatações estão materializadas nos 12 artigos que compõem o presente dossiê e que bem demonstram a contemporaneidade do xamanismo, o qual tem estimulado, por um lado, revisões de abordagens voltadas ao entendimento de sociedades indígenas (Fausto, 2001; Lima, 2005; Vilaça, 2000; Viveiros de Castro, 2002) e, por outro, tentativas de acompanhar sua disseminação, reconfiguração e circulação em contextos urbanos (Magnani, 2005).

A partir desses novos modelos de entendimento, o xamanismo, como sistema cosmológico, implica a manifestação de diversas práticas socioculturais associadas com as relações de atuação e mediação simbólica, que colocam em jogo saberes específicos e práticas rituais, vinculadas a concepções cosmoontológicas (Baptista da Silva, 2014), a modalidades de poder e de medicina, à produção de malefícios e a manifestações de arte (Lagrou, 2007). Além disso, 
o repertório do xamanismo pode incluir também diversas expressões como a religião, a adivinhação, a comunicação onírica e as práticas animistas, entre muitas outras. Essas múltiplas experiências denotam um xamanismo aberto, heterogêneo e às vezes contraditório, que cada vez parece estar mais atravessado por conexões e influências muito diversas (Fericgla, 2011). A recente aparição de novos discursos e práticas de xamanismo vinculadas a tendências contemporâneas como as religiosidades Nova Era, bem como a incorporação de xamãs indígenas a circuitos urbanos e transnacionais, voltam a situar no debate antropológico a instituição do xamanismo em novos e dinâmicos contextos.

O presente número de Horizontes Antropológicos traz à tona justamente as múltiplas expressões do xamanismo e do que poderíamos denominar de novos sistemas xamânicos. O diverso e heterogêneo acervo de artigos que ora publicamos demonstra diferentes contribuições teóricas e variadas etnografias que ressaltam as semelhanças e diferenças que ocorrem nas múltiplas manifestações do fenômeno xamânico, das cosmo-ontologias a ele associadas aos diversos possíveis papéis exercidos pelos xamãs em variados contextos.

Como estratégia de apresentação e discussão dos textos presentes neste número de Horizontes Antropológicos, eles foram aglutinados ao redor de três eixos que enfatizam três modos analíticos de compreensão, não totalmente distintos, dos fenômenos estudados.

O primeiro eixo reúne os artigos que centralmente discutem o xamanismo a partir de seus especialistas e de suas reflexões, com grande conotação etnográfica, partindo desde uma visão interna, desde dentro.

O segundo eixo analítico agrupa aqueles textos cuja principal intenção, nos parece, foi a de abordar o xamanismo através de sua relação com diversas alteridades, apresentando interfaces e refletindo sobre suas transformações.

Por sua vez, o terceiro e último eixo organiza em seu entorno artigos que enfatizam em suas análises conexões e conflitos cosmo-ontológicos, abordando aspectos como a agência cosmopolítica e a decolonialidade.

Entretanto, esses três eixos propostos para esta apresentação constituem-se mais como uma estratégia metodológica, uma vez que, certamente, há textos, discussões e abordagens que transbordam essas fronteiras arbitrárias e focos de análise e compreensão, transitando entre os eixos e estabelecendo entre si uma contínua interconexão. 
Nesse sentido, apresentamos primeiramente os artigos que incorporamos ao eixo cujo foco de análise se concentra na compreensão do xamanismo segundo seus especialistas e suas reflexões.

Em "Anaconda-becoming: Huni Kuin image-songs, an Amerindian relational aesthetics", Els Lagrou analisa, a partir de uma longa e intensa interlocução com especialistas do xamanismo kaxinawá, uma série de imagens-canções (huni meka) presentes no ritual da ayahuasca, potente cipó amazônico cuja ingestão implica, nas palavras da autora, um "profundo processo de devir-outro onde saber significa ver através dos olhos do Outro, cantar através da voz do Outro e ser coberto pela pele/ornamentos daqueles seres consumidos" e na "aquisição de capacidades agentivas e perceptivas de outros seres". Essas imagens-canções revelam todo um processo de percepção incorporada, no qual visão, música, som, ritmo e sensações corporais influenciam-se mutuamente e proporcionam cura e conhecimento.

Alessandro Roberto de Oliveira, em seu artigo de título "Técnicas de estragar os outros: sobre a ética xamânica na fronteira Brasil-Guiana", apresenta-nos a modalidade agressiva que ocorre no xamanismo do maciço guianense ocidental, conhecida como ataque kanaimé. Nesse contexto regional pluriétnico, o autor discute elementos cosmo-ontológicos que configuram relações entre humanos e plantas, discutindo, a partir de seus especialistas, a ética do xamã e o estatuto do humano.

Finalizando a apresentação dos artigos deste eixo analítico que enfatiza a compreensão do xamanismo a partir das reflexões de seus especialistas, Bruno Huyer, em "Dos alienígenas à jurualogia: reflexões de um provável xamã guarani-mbya", acompanha as "exegeses filosóficas" de um jovem guarani que procura entender quem são os não indígenas e os demais habitantes do cosmos, ao mesmo tempo em que etnografa e analisa sua iniciação xamânica.

A seguir, vêm as apresentações dos artigos agrupados no segundo eixo. Nele, a ênfase dos autores concentra-se em compreender o xamanismo em sua relação com alteridades, abordando suas interfaces e transformações.

Em "Derrota interna, sucesso exterior: a patrimonialização do xamanismo entre os Baniwa (Alto Rio Negro - Amazonas)", Elise Capredon busca entender os novos usos do xamanismo considerado como parte de dinâmicas mais amplas de revitalização cultural. Na região do Alto Rio Negro, o xamanismo local sofreu impactos por conta de discursos cristãos e da implantação exitosa 
do protestantismo. Por algum tempo, passou por uma simplificação e marginalização. Mais recentemente, a situação vem mudando, como mostram duas iniciativas de revitalização da pajelança: a criação de uma "Escola de Xamãs" e a realização de um documentário sobre a música baniwa incluindo cenas relativas a um ritual de iniciação. Tal revitalização depende de dinâmicas que conciliam manutenção e inovação; atores locais e remotos; lógicas internas e externas. Tem-se assim um caso de "xamanismo de interface", no qual as práticas e os saberes xamânicos foram "transferidos" para a área pública das relações exteriores, onde são mobilizados para atrair visitantes, ganhar visibilidade no cenário político regional e captar recursos.

Glauber Loures Assis e Jacqueline Alves Rodrigues, em "Uma bebida, muitas visões: apontamentos sociológicos sobre a II Conferência Mundial da Ayahuasca", discutem uma série de questões que percorrem a constituição das assim chamadas "redes neoxamânicas contemporâneas". A referência principal para a abordagem dessas redes é a caracterização de um campo ayahuasqueiro, do qual participam e interagem diversas vertentes: povos indígenas, religiões tradicionalistas, linhas expansionistas que geram variadas formas de apropriação, além dos estudiosos e organizações que visam acompanhar e promover os usos da ayahuasca. Os autores dedicam-se à análise de vários aspectos da realização de uma conferência ocorrida no Acre em 2016 e que reuniu diferentes agentes e visões sobre a ayahuasca. Enfatizam a diversidade, as tensões e conflitos que percorrem o campo ayahuasqueiro, com foco no Brasil, mas sem deixar de apontar dimensões transnacionais. A conferência, tal como abordada no texto, demonstra a emergência de diversos atores que têm se tornado relevantes nas redes neoxamânicas e vêm, segundo os autores, "construindo um verdadeiro pluralismo no campo ayahuasqueiro".

Aline Ferreira Oliveira, em "Os outros da festa: um sobrevoo por festivais yawanawa e huni kuin", discute alguns aspectos de uma intensa circulação de agentes, focando em certos sujeitos indígenas de grupos pano do Acre que realizam rituais xamânicos nas cidades e festivais nas aldeias para receberem visitantes não indígenas. Essa circulação produz conexões que geram novas passagens: não indígenas cujas visões espirituais incorporam elementos amazônicos; indígenas cujas visões espirituais incorporam elementos de outras origens, como os Andes, a América do Norte e mesmo o Oriente. Localmente, observam-se contatos entre religiosos ayahuasqueiros e indígenas, levando 
à revitalização de xamanismos amazônicos e à introdução neles de elementos religiosos ayahuasqueiros. Nesse quadro, os festivais encenam rituais tradicionais para performatizar novas alianças. Igualmente, noções (como a de espiritualidade) são compartilhadas sem manterem o mesmo entendimento - um processo de tradução que se dá por sentidos simultaneamente consoantes e dissonantes.

Em "Na fronteira: mobilidades xamânicas entre Brasil e Guiana Francesa", o último artigo deste eixo analítico, seu autor, Ugo Maia Andrade, explora as dinâmicas de trânsitos e trocas xamânicas na fronteira Brasil-Guiana tendo como centro a cidade de Oiapoque e a população karipuna, galibi-kali'na, galibi-marworno e palikur, que são apresentadas no texto, relacionando as suas interações com outras populações e coletividades não indígenas. Assim, o texto está centrado em um trabalho etnográfico que aprofunda a análise das dinâmicas de contato e dos "novos aportes de conhecimentos ao xamanismo regional", enfatizando esse campo de relações e refletindo sobre as transformações desse xamanismo e o surgimento de novas modalidades.

Por fim, apresentamos os artigos relacionados ao terceiro e último eixo analítico por nós proposto e que diz respeito aos textos que nas suas abordagens analisam o xamanismo a partir de suas conexões e conflitos cosmo-ontológicos, ressaltando seus aspectos cosmopolíticos em um contexto decolonial.

O primeiro deles tem por título "Medicinas da floresta: conexões e conflitos cosmo-ontológicos", no qual Guilherme Pinho Meneses acompanha os deslocamentos de xamãs huni kuĩ (kaxinawá) e de tais "medicinas", principalmente a ayahuasca, entre contextos "de floresta" e urbanos. Inspirando-se na proposição cosmopolítica de Isabelle Stengers, o autor sugere que o nixi pae (ayahuasca) aparece como "tecnologia de conectividade" entre coletivos diversos ontologicamente, possibilitando encontros com a alteridade e a "composição de espaços de coexistência".

Juan Scuro, em "(Neo)chamanismo. Aspectos constitutivos y desafíos analíticos", apresenta uma documentada discussão analítica sobre continuidades e rupturas entre xamanismos e neoxamanismos, através de referências teóricas, históricas e etnológicas, objetivando orientar a identificação e abordagem antropológicas do fenômeno, com ênfase na compreensão das "plantas maestras". O artigo constrói também uma paisagem dos principais debates antropológicos contemporâneos sobre os novos xamanismos. 
Em "Xamanismo e neoxamanismo no circuito do consumo ritual das medicinas da floresta", Saulo Conde Fernandes caracteriza o que chama de "circuito xamânico contemporâneo", estruturado a partir do consumo ritual de medicinas da floresta, um conjunto de psicoativos em que se destaca a ayahuasca. Alimentando-se das elaborações culturais do Santo Daime, de tradições indígenas amazônicas e de espiritualidades urbanas, esse circuito abre-se para articular um conjunto amplo e heterogêneo de atores, experiências e propostas. Nele se encontram neoxamãs (urbanos tradicionalizados) e neonativos (indígenas em circuitos urbanos). Trata-se de um território repleto de (re)invenção de tradições, onde elementos culturais de diversas culturas são mesclados, reelaborados, ressignificados. Culturas xamânicas ancestrais se unem ao universo Nova Era, dando origem a novos arranjos rituais.

Diego Madi Dias, em seu artigo "Entre a infância e o sonho: pedagogia guna da autonomia (Panamá)", destaca, entre esse coletivo, o "estatuto do sonho como experiência pessoal que serve de contexto ou 'moldura' para a prática pedagógica". O autor, além de destacar que na epistemologia guna o conhecimento é concebido como revelação, reflete sobre a conexão entre o "modelo onírico de inculcação" (canções de ninar) com a pragmática xamânica, chamando nossa atenção para a relação entre desenvolvimento infantil, condição de autonomia, sono, sonho, processos de aquisição, conhecimento como revelação e xamanismo entre os Guna.

Finalizando a apresentação dos artigos deste terceiro e último eixo analítico, temos o texto de Clémentine Ismérie Maréchal e Herbert Walter Hermann, "O xamanismo kaingang como potência decolonizadora", no qual seus autores propõem seu entendimento como "expressão cosmopolítica nos processos históricos coloniais". Nele, os autores abordam as práticas xamânicas kaingang e seus vẽnh péti (sonhos) como potências decoloniais e decolonizadoras que fazem parte dos recentes processos de reterritorialização no sul do Brasil.

No Espaço Aberto, publicamos a entrevista que Ailton Krenak, destacada liderança indígena brasileira, concedeu a Yussef Daibert Salomão de Campos, em 15 de abril de 2013, intitulada "O patrimônio cultural e o protagonismo indígena na Constituinte de 1987/88".

Por último, apresentamos a capa deste número de Horizontes Antropológicos. Ela exibe a pintura do russo Wassily Kandinsky (1866-1944) denominada Auf weiß II, de 1923. De acordo com Weiss (1986), estudiosa de sua obra, 
Kandinsky foi eleito muito jovem, em 1889, membro da Sociedade Imperial Russa de Amigos da História Natural, Antropologia e Etnografia, quando ainda estudante na Universidade de Moscou. No mesmo ano, foi selecionado por esta mesma sociedade para uma missão de pesquisa pelo norte de seu país (região de Vologda), onde entrou em contato com xamãs do povo zyrian, também conhecidos como Komi. Essas experiências etnográficas e esse encontro com o xamanismo e seu universo foram marcantes para o jovem estudante e decisivos para seu entendimento de arte, suas influências tendo persistido em sua obra até sua morte, tanto como pintor como escritor.

Weiss enfatiza o grande interesse do pintor, em seu ensaio sobre os Zyrian, em relação à "dupla fé" desse povo (o entrelaçamento entre os sistemas xamânico e cristão) e seu potente universo iconográfico, no qual o xamã siberiano, ao deixar seu corpo, viaja por outros mundos, auxiliado por seu tambor, que durante o transe transforma-se em cavalo, e relata à humanidade, no seu retorno, o conhecimento e as imagens que vivenciou e viu na sua jornada. Desse modo, Kandinsky relaciona o tambor xamânico com a tela do pintor, enquanto veículos de "renascimentos" e criação de "mundos", e autoidentifica seu papel como pintor com o do xamã, considerando a arte como um meio através do qual "man speaks to mankind about the supernatural" [o ser humano manifesta-se para a humanidade acerca do sobrenatural] (Weiss, 1986, p. 8-9, 13).

Considerado o "pai da arte abstrata", Kandinsky, em sua pintura reproduzida em nossa capa, leva-nos ao universo iconográfico xamânico, com seus tambores, cavalos, círculos, montanhas cósmicas, espírito de pássaros e nuvens, que atestam os voos do xamã para outros mundos.

\section{Referências}

BAPTISTA DA SILVA, S. Cosmo-ontologia e xamanismo entre coletivos kaingang. In: FLECK, E. C. D. (Org.). Religiões e religiosidades no Rio Grande do Sul: manifestações da religiosidade indígena. São Paulo: ANPUH, 2014. v. 3, p. 69-96. (Coleção Memória \& Cultura NEMEC/PPGH).

FAUSTO, C. Inimigos fiéis: história, guerra e xamanismo na Amazônia. São Paulo: Edusp, 2001. 
FERICGLA, J. M. Los chamanismos a revisión: de la vía del éxtasis a internet. Barcelona: Kairos, 2011.

LAGROU, E. A fluidez da forma: arte, alteridade e agência em uma sociedade amazônica (Kaxinawa, Acre). Rio de Janeiro: Topbooks, 2007.

LANGDON, E. J. M. (Org.). Xamanismo no Brasil: novas perspectivas. Florianópolis: Editora da UFSC, 1996.

LIMA, T. S. Um peixe olhou para mim: o povo yudjá e a perspectiva. São Paulo: Editora Unesp: ISA; Rio de Janeiro: NuTI, 2005.

MAGNANI, J. G. C. Xamãs na cidade. Revista USP, São Paulo, n. 67, p. 218-227, set./nov. 2005.

VILAÇA, A. O que significa tornar-se outro? Xamanismo e contato interétnico na Amazônia. Revista Brasileira de Ciências Sociais, São Paulo, v. 15, n. 44, p. 56-72, out. 2000.

VIVEIROS DE CASTRO, E. Perspectivismo e multinaturalismo na América indígena. In: VIVEIROS DE CASTRO, E. A inconstância da alma selvagem: e outros ensaios de antropologia. São Paulo: Cosac Naify, 2002. p. 345-399.

WEISS, P. Kandinsky and “Old Russia”: an ethnographic exploration. Syracuse Scholar(1979-1991), v. 7, n. 1, 1986. Disponível em: <http://surface.syr.edu/suscholar/vol7/ iss1/5>. Acesso em: 30 abr. 2018. 